\title{
Evaluation of the importance of ionic and osmotic components of salt stress on the photosynthetic efficiency of epiphytic lichens
}

\author{
Karolina Chowaniec $^{1}$ (D) Kaja Rola $^{1}$ (D)
}

Received: 29 November 2021 / Revised: 12 January 2022/ Accepted: 13 January 2022/Published online: 3 February 2022

(C) The Author(s) 2022

\begin{abstract}
Salt stress can significantly disrupt the functioning of lichens which are self-sufficient symbiotic organisms inhabiting various severe environments. The aim was to test the effect of salt and sucrose on the photosynthetic efficiency of two selected epiphytic lichens inhabiting the interior of the land. Firstly, we compared the effect of salt and sucrose solutions of different concentrations. Secondly, the effect of salt and sucrose solutions with identical osmotic pressures was compared. The results showed that short-term salt stress leads to a significant reduction of $F_{V} /$ $F_{M}$, greater changes in chlorophyll fluorescence parameters and OJIP transients compared to the osmotic effects induced by sucrose. This proved that the negative impact of salt stress is associated primarily with ionic effects. The most symptomatic effect of the ionic stress was a significant reduction of the utilisation of trapped energy in electron transport and thereby down-regulation of electron transfer. Since lichens are resistant to a temporary lack of water, ionic stress could have more serious consequences than osmotic stress itself. Hypogymnia physodes was more sensitive to salt stress than Pseudevernia furfuracea, but the reduction of photosynthetic efficiency was not permanent since after $24 \mathrm{~h} F_{V} / F_{M}$ returned to the level characteristic for healthy lichens. Nevertheless, repeated exposure to salt may reduce the vitality of lichens growing along communication routes sprinkled with salt in the winter season. Finally, the changes in certain JIP-test parameters were stronger than $F_{V} / F_{M}$, thus they could be better indicators of salt stress in lichens.
\end{abstract}

Kaja Rola

kaja.skubala@uj.edu.pl

1 Faculty of Biology, Institute of Botany, Jagiellonian University, Gronostajowa 3, 30-387 Kraków, Poland
Keywords Chlorophyll fluorescence - Ionic stress · Lichens - OJIP test - Osmotic stress · PSII maximal quantum yield

\section{Introduction}

Lichens are self-sufficient organisms that constitute a symbiotic relationship between a heterotrophic fungus and autotrophic algae and/or cyanobacteria. Due to the lack of root systems and protective cuticles they are especially sensitive to various pollutants and toxic substances (Tyler 1989). This physiological nature of lichens causes those substances present in a surrounding environment easily absorbed through the whole surface of the thalli (Nimis et al. 2002). Although lichens are sensitive to various pollutants and consequently have widely been used in biomonitoring studies, they are able to inhabit the most severe environments on Earth, from Antarctica to dry and hot deserts (Grube and Blaha 2005). Examples of such extreme areas are saline environments such as sea shores, dry areas such as deserts, semi-deserts, and steppes, as well as the immediate vicinity of roads where salt is used for snow removal.

In many areas of the world salt stress is an important factor that disrupts the functioning of organisms such as plants and lichens, and severely limits crops (Nash III and Lange 1988). The excess of salt in the environment has been one of the major concerns in recent years. Elevated salt concentrations lead to a decrease in hydric potential affecting water availability in lichens (Hasegawa et al. 2000). One of the main consequences of salt stress is the loss of intracellular water. Water loss is a dynamic phenomenon and certain acclimation can occur in lichens (Lange and Green 2005). Nevertheless, the accumulation 
of saline elements in thalli may induce both strong dehydration in lichens, but also ionic imbalances, and a deep loss in net photosynthesis of lichen photobionts (Matos et al. 2011). Moreover, high salinity induces hyperosmotic shock that generates oxidative stress and causes various metabolic disorders (Erdman and Hagemann 2001; Delmail et al. 2013). Therefore, lichens and especially photobionts associated with them are exposed to severe stress due to changes induced by increased salinity. Although several papers have attempted to assess the effect of salt stress on lichen photobionts, separating the effects of osmotic and ionic components on photosynthesis in lichens remains largely unexplored (see also Pan et al. 2021).

Lichens are poikilohydric organisms, so their hydration depends on the water content in the environment in which they grow (Honegger 2007). The exposure to dehydration leads to a gradual loss of photosynthetic activities of the photosynthetic partner, as evidenced by changes in the photosystem II (PSII) and is manifested by a decrease in the efficiency of transfer of the energy absorbed by it. The reduction of the maximum efficiency of PSII can lead to irreversible damage within it and consequently viability reduction of the whole thallus (Matos et al. 2011). The rate of respiration is also slowed down as a result of the gradual loss of pressure potential in the cells (Hajek et al. 2006). The induced osmotic shock, ionic imbalances, and the production of reactive oxygen species in lichen thallus can also contribute to disturbances in the integrity of cell membranes, damage to the cytoskeleton, or a reduction of protein or enzyme activity (Delmail et al. 2013; Yemets et al. 2015).

Lichens have developed many mechanisms that protect them against the negative effects of salinity (e.g. Grube and Blaha 2005). An example is the presence of an antioxidant system that protects the thallus from ROS, which can cause many cellular disturbances such as changes in the structure of enzymes involved in important metabolic pathways (Kranner et al. 2005; Delmail et al. 2013). In response to salinity, lichens produce specific metabolites called 'osmolytes' that serve as protection of proteins and are involved in maintaining continued water influx. Thanks to these substances, lowering of the internal osmotic potential is possible (Grube and Blaha 2005). Moreover, they could decrease the negative impact of ions on enzyme activity. Examples of this type of compounds include sucrose, fructose, glycerol, or trehalose (Hasegawa et al. 2000). Finally, microorganisms inhabiting lichen thallus may play a role in protecting the thallus against the influence of salinity, demonstrating the ability to store substances in the cytoplasm (e.g. trehalose or amino acids such as alanine) that protect against osmotic shock (Delmail et al. 2013).

One of the sources of salt in urban and rural environments is road salting used for safety precautions on the roads during winter seasons for the prevention of ice formation on the road surface, snow accumulation, and refreezing processes. Dissolved salt in melted water turn into airborne droplets by passing vehicles and sprayed away from the road. Moreover, aerial dispersion of salt comes from dry salt getting kicked up by tires and salty melted water. Various epiphytic lichens growing on trees along the roads are constantly exposed to salt stress. Although the resistance and adaptations at the morphological, anatomical, and biochemical levels of certain salt-resistant, coastal species have been recognized (see Delmail et al. 2013), there is still little information on species that naturally inhabit the interior of the land. Recognizing the effect of salt of anthropogenic origin on photosynthesis in various inland lichen species can help in the actual assessment of its effect on the physiology of these organisms.

The aim of this study was to test the effect of salt (solutions of different $\mathrm{NaCl}$ concentrations) and sucrose (solutions of different $\mathrm{C}_{12} \mathrm{H}_{22} \mathrm{O}_{11}$ concentrations) on chlorophyll fluorescence parameters in two selected epiphytic lichens. In the first stage we compared the effect of salt and sucrose solutions on photosynthetic efficiency through chlorophyll fluorescence measurements taking into account of experimental groups representing solutions of different concentrations. Since sucrose solutions cause only disturbances in the osmotic balance of cells, the effect of salt solutions additionally induces a negative effect due to the presence of sodium and chlorine ions. In another experiment, we tested the effect of salt and sucrose solutions with identical osmotic pressures on photosynthetic efficiency. This was tested to verify whether the salt treatment will have greater effects as compared to sucrose and further to estimate the influence of osmotic and ionic components of salt stress on photosynthetic efficiency.

\section{Materials and methods}

\section{Selected species}

Pseudevernia furfuracea (L.) Zopf. is a cosmopolitan epiphytic species. It has a flattened subfruticose thallus and reproduces vegetatively by isidia, which are produced on the upper surface of the thallus (Nimis 2016). The species is associated with photobionts representing green algae of the genus Trebouxia (Ahmadjian 1993). Pseudevernia furfuracea is commonly used as a biomonitor of airborne trace elements and other pollutants (Malaspina et al. 2014a; Incerti et al. 2017) and is widely utilised in bioindication studies assessing the degree of environmental pollution based on the changes of its physiological condition (Malaspina et al. 2018). 
Hypogymnia physodes (L.) Nyl. is a widespread epiphytic lichen with foliose thallus. It reproduces asexually by white powdery soredia formed under the outer thallus edges. The photobiont is represented by a green alga of the genus Trebouxia (Nimis 2016). Hypogymnia physodes is also commonly used in biomonitoring studies due to its ability to accumulate various trace elements such as lead or copper (e.g. Rusu et al. 2006).

\section{Sample collection and handling}

Pseudevernia furfuracea and $H$. physodes were collected in 2020 from living and fallen trees in a mid-forest clearing in Podsarnie $\left(49^{\circ} 32^{\prime} 2^{\prime \prime} \mathrm{N} ; 1^{\circ} 46^{\prime} 3^{\prime \prime} \mathrm{E}, 786\right.$ m.s.l.), located in the Orawsko-Podhalański Beskids, which is a range of Beskid Żywiecki Mts. (S Poland; Fig. S1). The data provided by the nearest air pollution measuring station indicate good air quality in the sampling area (data obtained from Voivodeship Inspectorate for Environmental Protection in Kraków). Freshly collected thalli were packed into paper bags and transported to the Soil Chemical Laboratory of the Institute of Botany of the Jagiellonian University.

\section{Experimental design}

Before each experiment, lichen thalli were kept for $24 \mathrm{~h}$ in a chamber with $95 \%$ relative humidity. This step is essential to reactivate physiological activity and to reestablish the integrity of cellular membranes (Buck and Brown 1979). The experiment was performed under normal laboratory light which varied from 55 to a maximum of $100 \mu \mathrm{mol} \mathrm{m}{ }^{-2} \mathrm{~s}^{-1}$ at room temperature of $20{ }^{\circ} \mathrm{C}$. In the first stage of the experiment pure salt solutions $(\mathrm{NaCl})$ with the following concentrations: $0.9,1.8,2.2,2.8,3.5,3.9 \mathrm{M}$ and pure sucrose solutions with the following concentrations: $0.15,0.30,0.35,0.45,0.55,0.60 \mathrm{M}$ were prepared. The $0 \mathrm{M}$ solution in each group was treated as a control group and constituted of distilled water. In the second stage of the experiment, $0.87 \mathrm{M}$ salt solution and $1.62 \mathrm{M}$ sucrose solution were used; the solutions were characterised by the same osmotic pressure $(\pi=39504 \mathrm{hPa})$. As a result, it was possible to directly compare the effects of ionic $(\mathrm{NaCl})$ and non-ionic (sucrose) stress induced by solutions characterised by the same osmotic pressure. The thalli of $P$. furfurace $a$ and $H$. physodes were then transferred to vessels with appropriate solutions and shaken on a vibrating shaker (Vibramax 100, Heidolph) for $2 \mathrm{~h}$ (rotation speed $300 \mathrm{rpm})$. Then, the thalli were transferred to a climatic chamber (approx. 95\% relative humidity). After $1 \mathrm{~h}$, the chlorophyll fluorescence was measured in 8 replications for each experimental group (the first day of the experiment).
Then the thalli were left in the climatic chamber and after $24 \mathrm{~h}$ the measurements were taken again (the second day of the experiment).

\section{Fluorescence measurements}

Chlorophyll fluorescence measurements were performed using Handy-PEA fluorimeter (Plant Efficiency Analyzer, Hansatech Instruments Ltd, Norfolk, England). Lichen samples were dark-adapted for $20 \mathrm{~min}$ before measurements. Chlorophyll fluorescence was induced by red light (wavelength $650 \mathrm{~nm}$ ) provided by an array of high-intensity LEDs. Data were recorded after a saturating light pulse $\left(2400 \mu \mathrm{mol} / \mathrm{m}^{2} / \mathrm{s}\right)$. All the fluorescence transients were recorded with a time span from $10 \mu$ s to $1 \mathrm{~s}$.

The vitality of the lichen photobiont was assessed by the maximum quantum yield of PSII photochemistry in the dark-adapted state: $F_{V} / F_{M}=\left(F_{M}-F_{0}\right) / F_{M}$, where $F_{O}$ and $F_{M}$ are minimal and maximal $\mathrm{Chl} a$ fluorescence intensity and $F_{V}=\left(F_{M}-F_{0}\right)$ is the variable fluorescence. The $F_{O}$ parameter constituted the value calculated using extrapolation back to time point 0 using least squares regression of the first few data points. The $F_{V} / F_{M}$ values corresponding to healthy lichens were considered to be $>0.6$ for chlorolichens (after Jensen and Kricke 2002). For a more precise analysis of the impact of stress on studied lichens, other parameters of chlorophyll fluorescence were analysed (Table 1).

\section{Data analysis}

With respect to the first stage of the experiment three main qualitative predictors were distinguished: 'Concentration': for salt: $0,0.9,1.8,2.2,2.8,3.5,3.9 \mathrm{M}$ and for sucrose: 0 , $0.15,0.30,0.35,0.45,0.55,0.60 \mathrm{M}$, 'Day': day 1 , day 2 and 'Species': Pseudevernia furfuracea, Hypogymnia physodes. The changes in the $F_{V} / F_{M}$ parameter, which determines the maximum efficiency of PSII, were analysed in detail. Two-way analyses of variance (two-way ANOVA; $P<0.05$ ) were performed to assess the effect of (1) 'Concentration' and 'Day' on the $F_{V} / F_{M}$ parameter for salt and sucrose solutions; separately for each species; (2) 'Concentration' and 'Species' on the $F_{V} / F_{M}$ parameter for salt and sucrose solutions; separately for each day of the experiment. Then, the significance of differences between particular experimental groups was verified with Tukey's HSD post-hoc tests $(P<0.05)$. The significance of differences in terms of photosynthetic parameters characterising PSII functionality between particular salt and sucrose treatments on the first day of the experiment was tested with one-way analyses of variance $(P<0.05)$ followed by Tukey's HSD post-hoc tests for both lichen species, separately. Before performing these analyses, the normality 
Table 1 The selected JIP-test parameters calculated on the basis of fast fluorescence kinetics used in further analyses

\begin{tabular}{|c|c|}
\hline $\begin{array}{l}\text { Fluorescence } \\
\text { parameter }\end{array}$ & Description \\
\hline \multicolumn{2}{|l|}{ Basic } \\
\hline$F_{0}$ & Minimal fluorescence intensity \\
\hline$F_{V} / F_{M}$ & Maximum quantum yield of PSII photochemistry \\
\hline \multicolumn{2}{|c|}{ The specific energy fluxes per reaction centre $(R C)$} \\
\hline $\mathrm{ABS} / \mathrm{RC}$ & Specific absorption flux per reaction centre \\
\hline $\mathrm{DI}_{0} / \mathrm{RC}$ & Dissipated energy flux per reaction centre \\
\hline $\mathrm{TR}_{0} / \mathrm{RC}$ & Trapped energy flux per reaction centre \\
\hline $\mathrm{ET}_{0} / \mathrm{RC}$ & Electron transport flux per reaction centre \\
\hline \multicolumn{2}{|c|}{ Quantum yields and efficiencies } \\
\hline Phi $\left(\mathrm{P}_{0}\right)$ & Probability that an absorbed photon will be trapped by the reaction centre of PSII \\
\hline Psi $\left(E_{0}\right)$ & Probability that a trapped exciton moves an electron into the electron transport chain beyond QA \\
\hline Phi $\left(\mathrm{E}_{0}\right)$ & Quantum yield of electron transport \\
\hline Phi $\left(\mathrm{R}_{0}\right)$ & Quantum yield of reduction of end electron acceptors at the PS I acceptor side \\
\hline \multicolumn{2}{|c|}{ Phenomenological energy fluxes per excited cross-section (CS) } \\
\hline $\mathrm{ABS} / \mathrm{CS}$ & Specific absorption flux per excited cross-section \\
\hline $\mathrm{DI}_{0} / \mathrm{CS}$ & Dissipated energy flux per excited cross-section \\
\hline $\mathrm{TR}_{0} / \mathrm{CS}$ & Trapped energy flux per excited cross-section \\
\hline $\mathrm{ET}_{0} / \mathrm{CS}$ & Electron transport flux per excited cross-section \\
\hline \multicolumn{2}{|c|}{ Performance index } \\
\hline $\mathrm{PI}_{\mathrm{ABS}}$ & $\begin{array}{l}\text { Performance index (potential) for energy conservation from photons absorbed by PSII to the reduction of intersystem } \\
\text { electron acceptors }\end{array}$ \\
\hline
\end{tabular}

distribution in particular groups was checked using the Kolmogorov-Smirnov test. Levene's test was used to verify the homogeneity of variances. Box-Cox transformation was applied if necessary.

As regards the second stage of the experiment, the obtained values of photosynthetic parameters characterising PSII functionality for $0.87 \mathrm{M}$ salt solution and $1.62 \mathrm{M}$ sucrose solution were converted in relation to the control values. The mean value for the control samples $(n=8)$ was adopted for calculations. Then, Student's t-tests $(P<0.05)$ were used to verify the significance of differences between salt and sucrose solutions for each species and day of the experiment, separately. Next, Student's t-tests $(P<0.05)$ were applied to test the significance of differences in photosynthetic parameters characterising PSII functionality between $0.87 \mathrm{M}$ salt solution and control as well as for $1.62 \mathrm{M}$ sucrose solution and control treatment, for each species and day of experiment, separately. Prior to the analysis, the normality distribution o was checked using the Kolmogorov-Smirnov test and Levene's test was used to verify homogeneity of variances. Box-Cox transformation was applied if necessary. Statistical analyses were performed in the STATISTICA 12 (StatSoft, Tulsa, OK).
For both stages of the experiment the chlorophyll fluorescence induction curves were plotted for particular experimental groups (averaged values for $n=8$ measurements) including the division into species and days of the experiment. This was based on the results of chlorophyll fluorescence signals at short time intervals, starting from $10 \mu \mathrm{s}$, and ending before $1 \mathrm{~s}$. The fast fluorescence kinetic outlines a transient curve plotted on a log-time axis to visualise a sequence of steps called OJIP (Strasser et al. 2000).

Regarding the results of the first stage of the experiment, spider plots were created to illustrate the effect of salt and sucrose stress on various parameters characterising PSII functionality on the first day of the experiment, for each species separately. The graphs were used to verify if there are more sensitive parameters than $F_{V} / F_{M}$ that could indicate the effect of stress. The plots were based on the values normalised to the control treatment, enabling the comparison of parameters measured on different scales. 


\section{Results}

\section{Impact of different salt and sucrose treatments on photosynthetic efficiency during the first stage of the experiment}

Comparison of the simultaneous effect of 'Concentration' and 'Species' on the $F_{V} / F_{M}$ parameter for salt solutions showed a significant interaction between these independent variables on both days of the experiment (Table S1). Significantly the lowest values of $F_{V} / F_{M}$ were recorded for solutions with a concentration of $3.9 \mathrm{M}$ in the case of $H$. physodes (Fig. 1a, b). When the effect of sucrose on the $F_{V} / F_{M}$ parameter was analysed for the first day of the experiment, no significant differences between particular concentrations were noted, while the effect of 'Species' proved to be significant (Table S1, Fig. 1c). For each concentration, the $F_{V} / F_{M}$ values were lower in the case of $P$. furfuracea. On the second day of the experiment a significant interaction between 'Species' and 'Concentration' was recorded, but the post-hoc test did not show significant differences (Table S1, Fig. 1d).
In $H$. physodes, the $F_{V} / F_{M}$ parameter was influenced by both the 'Day' and 'Concentration' of salt solution (significant 'Day' $\times$ 'Concentration' interaction; Table S1). This parameter was significantly lower on the first day of the experiment for the $3.9 \mathrm{M}$ concentration compared to the remaining concentrations in two consecutive days of the experiment, with the exception of the $3.5 \mathrm{M}$ concentration on the first day of the experiment (Fig. S2a). No significant differences were found between particular sucrose concentrations, while the effect of 'Day' proved to be significant (Table S1, Fig. S2b). Analysing the effect of salt concentration and the day of experiment on the $F_{V} / F_{M}$ parameter in $P$. furfuracea, the interaction between 'Concentration' and 'Day' turned out to be significant (Table S1, Fig. S2c). Significantly lowest $F_{V} / F_{M}$ values were recorded for the concentration of $3.5 \mathrm{M}$ on the first day of the experiment; they differed significantly from all other concentrations on both days of the experiment, except for the concentration of $3.9 \mathrm{M}$ on the first day of the experiment. Concerning the effect of sucrose, significant differences between particular concentrations were noted, regardless of the experiment day (Table S1, Fig. S2d). The $F_{V} / F_{M}$ parameter was significantly lower after treatment with $0.15 \mathrm{M}$ solution compared to $0.55 \mathrm{M}$ solution.
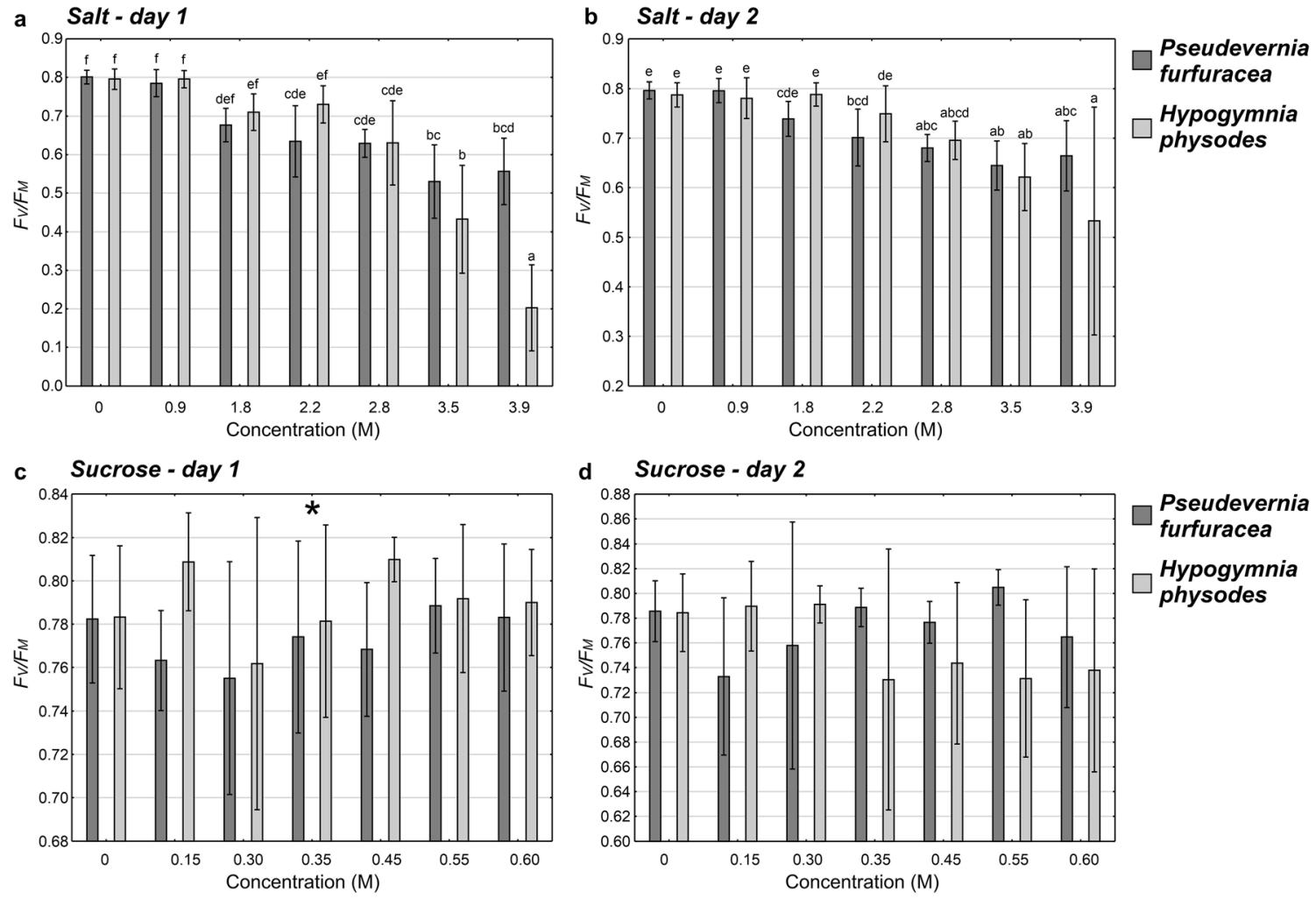

Fig. 1 The $F_{V} / F_{M}$ parameter in particular experimental groups (means $\pm \mathrm{SE} ; n=8$ ) for different concentrations of salt $(\mathbf{a}, \mathbf{b})$ and sucrose $(\mathbf{c}, \mathbf{d})$ solutions in two subsequent days of the experiment for Hypogymnia physodes and Pseudevernia furfuracea. The different letters above the bars indicate statistically significant differences
$(P<0.05)$. Lowercase letters indicate a statistically significant interaction between lichen species and solution concentration. The asterisk indicates the significant main effect of species. See Table S1 for details on the main effects and interactions 
The salt stress caused a significant increase in the values of the $\mathrm{ABS} / \mathrm{RC}, \mathrm{DI}_{0} / \mathrm{RC}$, and $\mathrm{DI}_{0} / \mathrm{CS}$ parameters in $H$. physodes on the first day of the experiment and a significant decrease of the $F_{0}, F_{V} / F_{M}, \mathrm{TR}_{0} / \mathrm{RC}, \mathrm{ET}_{0} / \mathrm{RC}, \mathrm{Phi}\left(\mathrm{P}_{0}\right)$, Psi $\left(\mathrm{E}_{0}\right)$, Phi $\left(\mathrm{E}_{0}\right)$, Phi $\left(\mathrm{R}_{0}\right)$, ABS/CS, $\mathrm{TR}_{0} / \mathrm{CS}, \mathrm{ET}_{0} / \mathrm{CS}$, $\mathrm{PI}_{\mathrm{ABS}}$ parameters versus control (Table 2). This effect was particularly noticeable for $3.5 \mathrm{M}$ and $3.9 \mathrm{M}$ solutions (Fig. S3a). In the case of $P$. furfuracea, the results were similar, except for $F_{O}$ and ABS/CS the values of which were significantly increased in all experimental groups compared to the control (Fig. S3b). Significant differences were recorded for all parameters except for $\mathrm{TR}_{0} / \mathrm{CS}$ (Table 2). The changes in chlorophyll fluorescence parameters after treatment with sucrose solutions did not differ as considerably from the control compared to the effect of salt solutions (Fig. S4). There were no significant differences in the analysed parameters between any of the sucrose treatments and the control for $H$. physodes (one-way ANOVA, $P>0.05$; data not shown). As regard $P$. furfuracea, the stress induced by sucrose caused significant changes between control and single experimental groups of only 5 out of 15 tested parameters, i.e. $F_{0}, \mathrm{TR}_{0} /$ RC, ABS/CS, $\mathrm{TR}_{0} / \mathrm{CS}, \mathrm{ET}_{0} / \mathrm{CS}$ (Fig. S4b).

\section{Impact of salt and sucrose solutions with the same osmotic pressure on photosynthetic efficiency during the second stage of the experiment}

Significant differences in $F_{V} / F_{M}$ expressed as a percentage of the control were observed between salt and sucrose solutions with the same osmotic pressure only in the case of $H$. physodes on the first day of the experiment (Student t-test, $P<0.05$; Table 3). For all species and experimental days, the mean values were also always lower for salt compared to the sucrose solution, but these differences were not significant. Regarding other fluorescence parameters, significant differences between the salt and sugar treatment effect in relation to the control were noted for $\mathrm{ET}_{0} / \mathrm{RC}$, Psi $\left(\mathrm{E}_{0}\right)$, Phi $\left(\mathrm{E}_{0}\right)$, Phi $\left(\mathrm{R}_{0}\right)$ for $P$. furfuracea on the first day of the experiment. Each of these parameters was decreased in the salt-treated thalli relative to the control, unlike the sugar-treated samples, the values of which oscillated around the control values (Student t-test, $P<0.05$; Table 3). As regard $H$. physodes, significant differences in salt and sugar effects relative to the control were recorded for the following parameters: $F_{0}, \mathrm{ET}_{0} / \mathrm{RC}$, Phi $\left(\mathrm{P}_{0}\right)$, Psi $\left(\mathrm{E}_{0}\right)$, Phi $\left(\mathrm{E}_{0}\right), \mathrm{ABS} / \mathrm{CS}, \mathrm{TR}_{0} / \mathrm{CS}, \mathrm{ET}_{0} / \mathrm{CS}$, and $\mathrm{PI}_{\mathrm{ABS}}$, which values were significantly lower for salt-treated as compared to sugar-treated thalli (Student t-test, $P<0.05$; Table 3). The induced disturbances were not permanent, because for both species on the second day of the experiment, no significant differences were noted (Table 3). Comparing the changes caused by the studied salt and sucrose solutions on the parameters of chlorophyll fluorescence in relation to the corresponding control values, significant reductions of $\mathrm{ET}_{0} / \mathrm{RC}$, Psi $\left(\mathrm{E}_{0}\right)$, Phi $\left(\mathrm{E}_{0}\right)$, and Phi $\left(\mathrm{R}_{0}\right)$ in $P$. furfuracea and $\mathrm{ET}_{0} / \mathrm{RC}$ in $H$. physodes were observed (Student t-test, $P<0.05$ ). On the other hand, sucrose treatment did not caused any significant changes in chlorophyll fluorescence parameters compared to the control (Table S2).

\section{Fluorescence kinetics: OJIP test}

Regarding the first stage of the experiment, a reduced value of minimal fluorescence intensity $\left(F_{0}\right)$ was observed in most of the experimental groups after salt treatment compared to the control on both days of the experiment in the case of $H$. physodes (Fig. S5). A reverse tendency was observed for $P$. furfuracea, where after treatment with salt solutions the $F_{O}$ values were higher in most experimental groups compared to the control (Fig. S6). As regards $H$. physodes treated with different concentrations of salt solutions, the fluorescence curves had a different course. On the first day of the experiment, for the concentrations of $3.5 \mathrm{M}$ and $3.9 \mathrm{M}$, a clear decrease in the $F_{M}$ value was visible. Moreover, the emission peak was not clearly marked and the induction curves of chlorophyll fluorescence were almost flat (Fig. S5). On the second day of the the experiment, a slight increase in the $F_{M}$ value in these experimental groups can be observed. Chlorophyll fluorescence induction curves for $H$. physodes treated with sucrose solutions did not show significant deviations in relation to the control group, only a slight decrease in the $F_{M}$ value was observed in single experimental groups compared to the control on the first day of the experiment. On the second day of experiment, the course of the chlorophyll induction curves was very similar in all experimental groups (Fig. S5). In the case of $P$. furfuracea thalli treated with salt on the first day of the experiment, a reduced value of the $F_{M}$ was observed compared to the control, except for $0.9 \mathrm{M}$ concentration (Fig. S6). After treatment of lichens with sucrose solutions, both on the first and the second day of the experiment, the $F_{O}$ values were higher than in the control group. On the first day of the experiment, most of the chlorophyll induction curves ran considerably higher than in the control, with the exception of the groups representing the concentrations of $1.8 \mathrm{M}$ and $2.8 \mathrm{M}$, for which the course was similar to the control group (Fig. S6).

As regards the second stage of the experiment, the comparison of the effect of salt and sucrose solutions of the same osmotic pressure on the course of transient curves indicated that the curves had a flatter course and reached lower $F_{M}$ values in the case of the salt solution compared to sucrose solution for both lichen species (Fig. 2a, b). The 


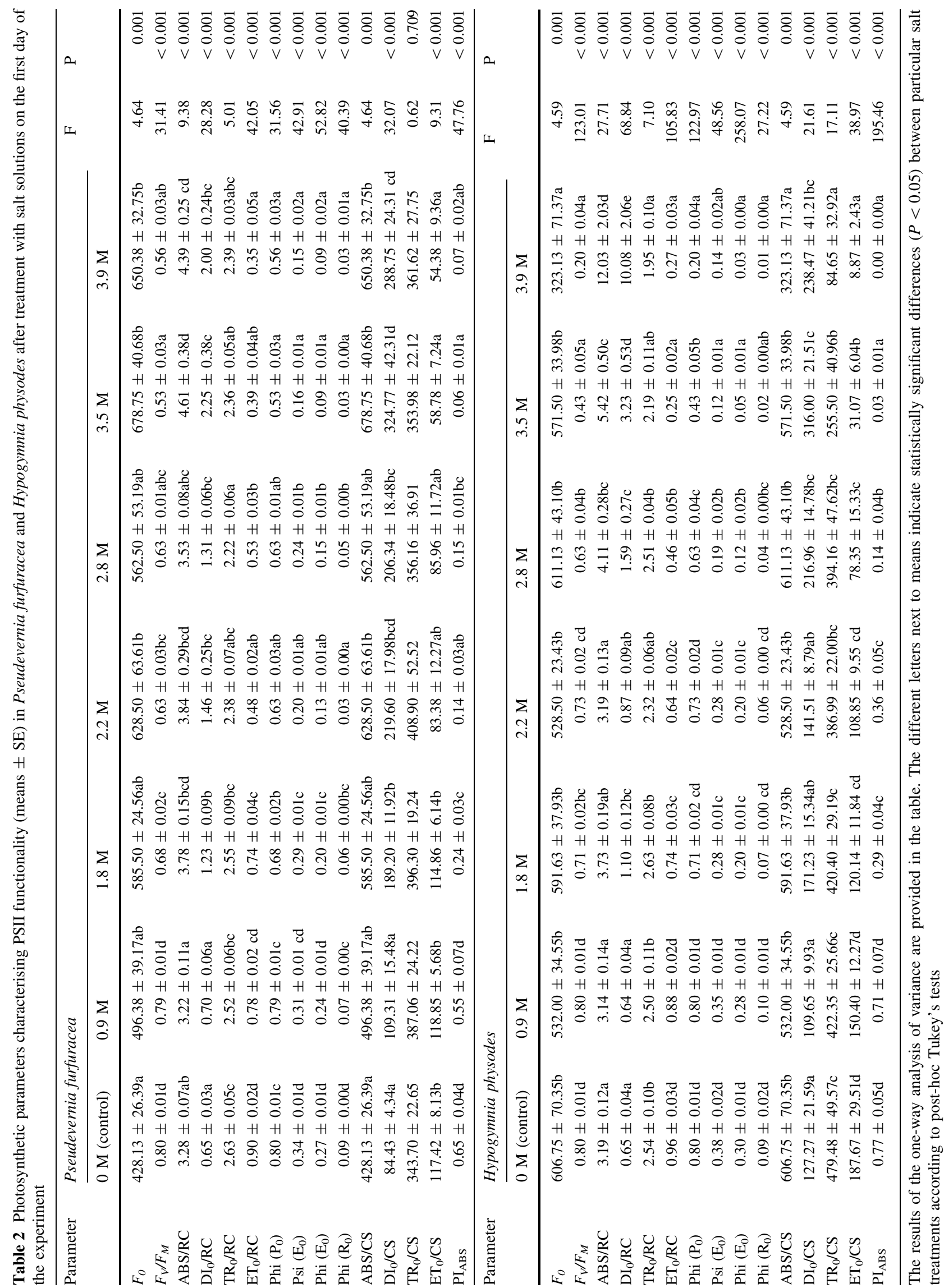


Table 3 Comparison of various photosynthetic parameters characterising PSII functionality (expressed as a percentage of the control; means $\pm \mathrm{SD}$ ) in the species Pseudevernia furfuracea and
Hypogymnia physodes after treatment with salt $(0.87 \mathrm{M})$ and sucrose $(1.62 \mathrm{M})$ solutions of the same osmotic pressure on the first and the second day of the experiment

\begin{tabular}{|c|c|c|c|c|c|c|c|c|c|}
\hline \multirow[t]{2}{*}{ Parameter } & \multirow[t]{2}{*}{ Day of experiment } & \multicolumn{4}{|c|}{ Pseudevernia furfuracea } & \multicolumn{4}{|c|}{ Hypogymnia physodes } \\
\hline & & Salt & Sucrose & $\mathrm{t}$ & $\mathrm{P}$ & Salt & Sucrose & $\mathrm{t}$ & $\mathrm{P}$ \\
\hline \multirow[t]{2}{*}{$F_{0}$} & Day 1 & $115.9 \pm 25.9$ & $102.2 \pm 21.3$ & 1.16 & 0.265 & $87.7 \pm 16.1$ & $113.1 \pm 13.6$ & -3.42 & 0.004 \\
\hline & Day 2 & $106.3 \pm 17.7$ & $102.8 \pm 15.6$ & 0.42 & 0.680 & $91.0 \pm 16.1$ & $88.8 \pm 6.8$ & 0.35 & 0.732 \\
\hline \multirow[t]{2}{*}{$F_{V} / F_{M}$} & Day 1 & $98.0 \pm 4.3$ & $99.7 \pm 3.0$ & -0.91 & 0.378 & $100.0 \pm 2.8$ & $104.2 \pm 2.4$ & -3.25 & 0.006 \\
\hline & Day 2 & $99.9 \pm 3.0$ & $99.8 \pm 1.2$ & 0.11 & 0.913 & $99.1 \pm 5.2$ & $102.8 \pm 3.5$ & -1.66 & 0.119 \\
\hline \multirow[t]{2}{*}{$\mathrm{ABS} / \mathrm{RC}$} & Day 1 & $98.1 \pm 9.5$ & $102.7 \pm 6.9$ & -1.12 & 0.283 & $98.5 \pm 12.6$ & $95.2 \pm 9.0$ & 0.59 & 0.563 \\
\hline & Day 2 & $103.9 \pm 8.2$ & $99.9 \pm 9.3$ & 0.93 & 0.370 & $104.6 \pm 15.5$ & $96.0 \pm 10.9$ & 1.29 & 0.220 \\
\hline \multirow[t]{2}{*}{$\mathrm{DI}_{0} / \mathrm{RC}$} & Day 1 & $106.9 \pm 27.3$ & $104.3 \pm 15.0$ & 0.24 & 0.813 & $98.8 \pm 18.3$ & $82.9 \pm 12.8$ & 2.01 & 0.064 \\
\hline & Day 2 & $104.2 \pm 17.9$ & $100.7 \pm 10.9$ & 0.48 & 0.641 & $110.3 \pm 36.5$ & $86.5 \pm 17.4$ & 1.66 & 0.118 \\
\hline \multirow[t]{2}{*}{$\mathrm{TR}_{0} / \mathrm{RC}$} & Day 1 & $95.9 \pm 6.4$ & $102.3 \pm 6.9$ & -1.93 & 0.074 & $98.4 \pm 12.2$ & $99.5 \pm 8.5$ & -0.21 & 0.840 \\
\hline & Day 2 & $103.9 \pm 7.0$ & $99.7 \pm 9.2$ & 1.03 & 0.323 & $103.1 \pm 11.1$ & $99.0 \pm 10.6$ & 0.77 & 0.453 \\
\hline \multirow[t]{2}{*}{$\mathrm{ET}_{\mathrm{o}} / \mathrm{RC}$} & Day 1 & $86.7 \pm 4.9$ & $103.2 \pm 9.5$ & -4.37 & 0.001 & $91.3 \pm 6.5$ & $117.4 \pm 13.2$ & $-\mathbf{5 . 0 3}$ & $<0.001$ \\
\hline & Day 2 & $100.4 \pm 8.4$ & $99.7 \pm 6.2$ & 0.17 & 0.864 & $105.6 \pm 10.4$ & $98.5 \pm 4.3$ & 1.79 & 0.095 \\
\hline \multirow[t]{2}{*}{ Phi $\left(\mathrm{P}_{0}\right)$} & Day 1 & $98.0 \pm 4.3$ & $99.7 \pm 3.0$ & -0.92 & 0.376 & $100.0 \pm 2.8$ & $104.2 \pm 2.4$ & -3.26 & 0.006 \\
\hline & Day 2 & $99.9 \pm 3.1$ & $99.8 \pm 1.2$ & 0.11 & 0.910 & $99.1 \pm 5.2$ & $102.8 \pm 3.5$ & -1.66 & 0.118 \\
\hline \multirow[t]{2}{*}{ Psi $\left(E_{0}\right)$} & Day 1 & $90.7 \pm 8.5$ & $100.8 \pm 8.7$ & -2.36 & $\mathbf{0 . 0 3 3}$ & $92.7 \pm 7.4$ & $118.7 \pm 14.3$ & -4.56 & $<0.001$ \\
\hline & Day 2 & $96.6 \pm 7.8$ & $100.1 \pm 13.5$ & -0.64 & 0.535 & $104.1 \pm 7.6$ & $99.1 \pm 8.5$ & 1.26 & 0.230 \\
\hline \multirow[t]{2}{*}{ Phi $\left(E_{0}\right)$} & Day 1 & $89.1 \pm 11.3$ & $100.5 \pm 8.6$ & -2.28 & $\mathbf{0 . 0 3 9}$ & $92.9 \pm 7.3$ & $120.9 \pm 15.5$ & -4.61 & $<0.001$ \\
\hline & Day 2 & $96.5 \pm 8.6$ & $99.9 \pm 13.9$ & -0.59 & 0.567 & $102.7 \pm 11.2$ & $101.6 \pm 9.1$ & 0.22 & 0.828 \\
\hline \multirow[t]{2}{*}{ Phi $\left(\mathrm{R}_{0}\right)$} & Day 1 & $75.4 \pm 10.2$ & $100.3 \pm 18.6$ & -3.33 & 0.005 & $104.0 \pm 17.8$ & $119.6 \pm 77.2$ & -0.56 & 0.587 \\
\hline & Day 2 & $88.1 \pm 13.2$ & $103.1 \pm 26.2$ & -1.44 & 0.171 & $95.6 \pm 14.5$ & $106.0 \pm 18.0$ & -1.27 & 0.226 \\
\hline \multirow[t]{2}{*}{$\mathrm{ABS} / \mathrm{CS}$} & Day 1 & $115.9 \pm 25.9$ & $102.2 \pm 21.3$ & 1.16 & 0.265 & $87.7 \pm 16.1$ & $113.1 \pm 13.6$ & -3.42 & 0.004 \\
\hline & Day 2 & $106.3 \pm 17.7$ & $102.8 \pm 15.6$ & 0.42 & 0.680 & $91.0 \pm 16.1$ & $88.8 \pm 6.8$ & 0.35 & 0.732 \\
\hline \multirow[t]{2}{*}{$\mathrm{DI}_{0} / \mathrm{CS}$} & Day 1 & $129.5 \pm 51.9$ & $103.8 \pm 29.4$ & 1.22 & 0.244 & $86.2 \pm 22.1$ & $92.3 \pm 18.0$ & -0.61 & 0.549 \\
\hline & Day 2 & $106.7 \pm 23.7$ & $103.5 \pm 15.2$ & 0.32 & 0.753 & $92.1 \pm 26.9$ & $80.3 \pm 14.0$ & 1.10 & 0.289 \\
\hline \multirow[t]{2}{*}{$\mathrm{TR}_{0} / \mathrm{CS}$} & Day 1 & $112.6 \pm 19.9$ & $101.7 \pm 20.1$ & 1.09 & 0.295 & $88.1 \pm 15.1$ & $121.0 \pm 12.2$ & -4.78 & $<0.001$ \\
\hline & Day 2 & $106.2 \pm 17.4$ & $102.6 \pm 16.0$ & 0.43 & 0.673 & $90.7 \pm 15.6$ & $91.4 \pm 6.6$ & -0.12 & 0.904 \\
\hline \multirow[t]{2}{*}{$\mathrm{ET}_{0} / \mathrm{CS}$} & Day 1 & $101.2 \pm 13.7$ & $102.7 \pm 25.5$ & -0.15 & 0.883 & $80.1 \pm 18.5$ & $159.8 \pm 24.0$ & -7.43 & $<0.001$ \\
\hline & Day 2 & $103.0 \pm 25.8$ & $102.6 \pm 27.9$ & 0.03 & 0.978 & $100.3 \pm 20.3$ & $89.4 \pm 12.3$ & 1.30 & 0.213 \\
\hline \multirow[t]{2}{*}{$\mathrm{PI}_{\mathrm{ABS}}$} & Day 1 & $84.7 \pm 29.2$ & $98.0 \pm 20.3$ & -1.06 & 0.309 & $91.5 \pm 26.1$ & $135.3 \pm 41.3$ & -2.54 & 0.024 \\
\hline & Day 2 & $91.5 \pm 26.7$ & $99.4 \pm 37.4$ & -0.48 & 0.635 & $97.1 \pm 35.5$ & $109.7 \pm 33.3$ & -0.73 & 0.476 \\
\hline
\end{tabular}

The results of Student's t-tests are provided in the table. Significant differences $(P<0.05)$ between the effect of salt and sucrose treatments are provided in bold

increased values at the O-J phase were observed in both lichen species treated with salt solution compared to sucrose solution on the first and the second day of the experiment (Fig. 2c, d).

\section{Discussion}

\section{Effect of salt and sucrose stress on photosynthetic efficiency}

The analysis of chlorophyll fluorescence is one of the most powerful and commonly utilised techniques to study the effect of stressful factors on the photosynthetic process. Many studies have investigated the effect of salt stress in different plant species (e.g. Kalaji et al. 2018; Zhao et al. 2019; Akhter et al. 2021); however, there are only a few studies that tested the effect of salt stress on lichens (e.g. Matthes-Sears et al. 1987; Nash III and Lange 1988; Smith and Gremmen 2001; Matos et al. 2011; Malaspina et al. 2015). Most of the previous studies analysed the issue in the context of lichens naturally exposed to sea salt, and even if they were experimental studies, they were concerned about the impact of seawater on lichen physiology. Moreover, the existing reports showed differentiated results in terms of the negative impact of salt on lichen 
photosynthesis. For example, Smith and Gremmen (2001) found that salinity did not significantly influence the $\mathrm{CO}_{2}$ assimilation rate in a shore-zone lichen Turgidiusculum complicatulum. On the contrary, incubation in a $100 \%$ artificial seawater solution of Ramalina canariensis caused a considerable and irreversible reduction in $F_{V} / F_{M}$ (Matos et al. 2011). The situation is more complicated since Nash III and Lange (1988) showed that the degree of sensitivity to salt stress of a certain species is proportional to the distance from the sea coast where the lichens grow. It can certainly be concluded that the sensitivity to salt stress is highly variable between species, but the response of species naturally occurring inland and exposed to salinity due to road salting remained poorly explored.

In regards to the photosynthetic process, osmotic stress can cause inactivation of PSII, photoinhibition, and electron flow retardation through PSII (Delmail et al. 2013); however, during dehydration, lichens can activate the specific mechanism for protection of PSII against ROS (Hajek et al. 2006). Osmotic stress leads to the loss of intracellular water, and when the water content is less than $10 \%$, many enzymatic reactions and metabolism in cells are stopped (Green et al. 2011). The polyhydric nature of lichens makes them resistant to temporary lack of water availability, but ionic stress associated with the accumulation of ions in the cells has much more serious consequences especially when we compare these consequences for vascular plants, where even short-term drought stress itself can be fairly critical. Furthermore, in the case of vascular plants, the response to both salinity and drought stress proved to be similar at the early stage of Tilia cordata exposure to those stress factors and the response of PSII occurred even earlier in plants subjected to drought stress (Kalaji et al. 2018). Lichens are highly desiccationtolerant organisms and most species can withstand drying to water contents of $5 \%$ or less remaining viable for a long time (Kranner et al. 2008). Based on our results, we can conclude that the short-term osmotic stress caused by sucrose does not cause considerable effects on photosynthetic efficiency in comparison with salt stress. This is in line with previous studies that showed that only prolonged staying in the desiccated state causes significant degradation of chlorophyll (Kranner et al. 2003; Beckett et al. 2005).

We have shown that the short-term salt stress leads to a significant reduction of $F_{V} / F_{M}$ which is a sensitive indicator of photosynthetic performance. This indicates photoinhibition of PSII, which is associated with damage to the reaction centres. Regarding the comparison between the studied lichen species, both the first and the second stage of the experiment confirmed that $H$. physodes is more sensitive to salt stress than $P$. furfuracea. Although both species involve photobionts of the genus Trebouxia and are typical inland species, one of them turned out to be more sensitive to salt stress. The greater sensitivity of $H$. physodes was evidenced not only by the greater decrease in the $F_{V} / F_{M}$ values but also by greater changes in chlorophyll fluorescence parameters and stronger deviation in the OJIP transient curve compared to the control. The high resistance $P$. furfuracea is in line with previous results of the study in which $P$. furfuracea proved to be more sensitive to atmospheric pollution than to the proximity to the sea (Malaspina et al. 2015). Sensitivity to stress may vary significantly between lichen species. Matos et al. (2011) reported that the incubation in $100 \%$ artificial seawater reduced $F_{V} / F_{M}$ in Ramalina canariensis even after 5 min of incubation. Moreover, subsequent incubation of the samples in deionized water did not recover $F_{V} / F_{M}$ to control values (Matos et al. 2011). Interestingly, lichen photobiont Halofilum ramosum, which is known so far only from marine environments, showed no clear reduction in $F_{V} / F_{M}$ in relation to $\mathrm{NaCl}$ concentration (Gasulla et al. 2019). Although there are several studies on the effect of salt stress that have analysed changes in photosynthetic efficiency over time, verifying the effect of multiple stress episodes over a longer period of time along with photosynthetic efficiency screening requires more in-depth studies. This would help to reflect the actual conditions to which lichens growing along salted communication routes are exposed and this issue is the subject of our further studies. The present study showed that exposure to shortterm salt stress reduces the maximum quantum yield of PSII photochemistry, but does not cause permanent changes, because after $24 \mathrm{~h}$ from exposure to stress, $F_{V} / F_{M}$ values increased and in most experimental groups returned to the level characteristic of healthy lichens.

Another factor that affects the resistance of lichens to salt stress is the photobiont identity present in the thallus. The study on isolated Trebouxia sp. TR9 photobiont showed that this strain displays a superior performance under high salt concentrations and prolonged exposure did not significantly affect PSII activity and chlorophyll contents after a period of $72 \mathrm{~h}$ (Hinojosa-Vidal et al. 2018). However, it should be borne in mind that the isolated photobionts may react differently than those present in the lichen thallus. Kosugi et al. (2009) found different responses to dehydration between isolated Trebouxia sp. cells and those present in lichen Ramalina yasudae, the former of which were more sensitive to photoinhibition. This indicates that symbiotic association increases tolerance of photobiont (Kosugi et al. 2009).

Our results showed that compared to salt stress, the sucrosetreated lichen samples showed no significant reduction of the $F_{V} / F_{M}$ parameter even at high concentrations. Hajek et al. (2006) found that increasing sucrose concentrations and time of exposure led to a pronounced 

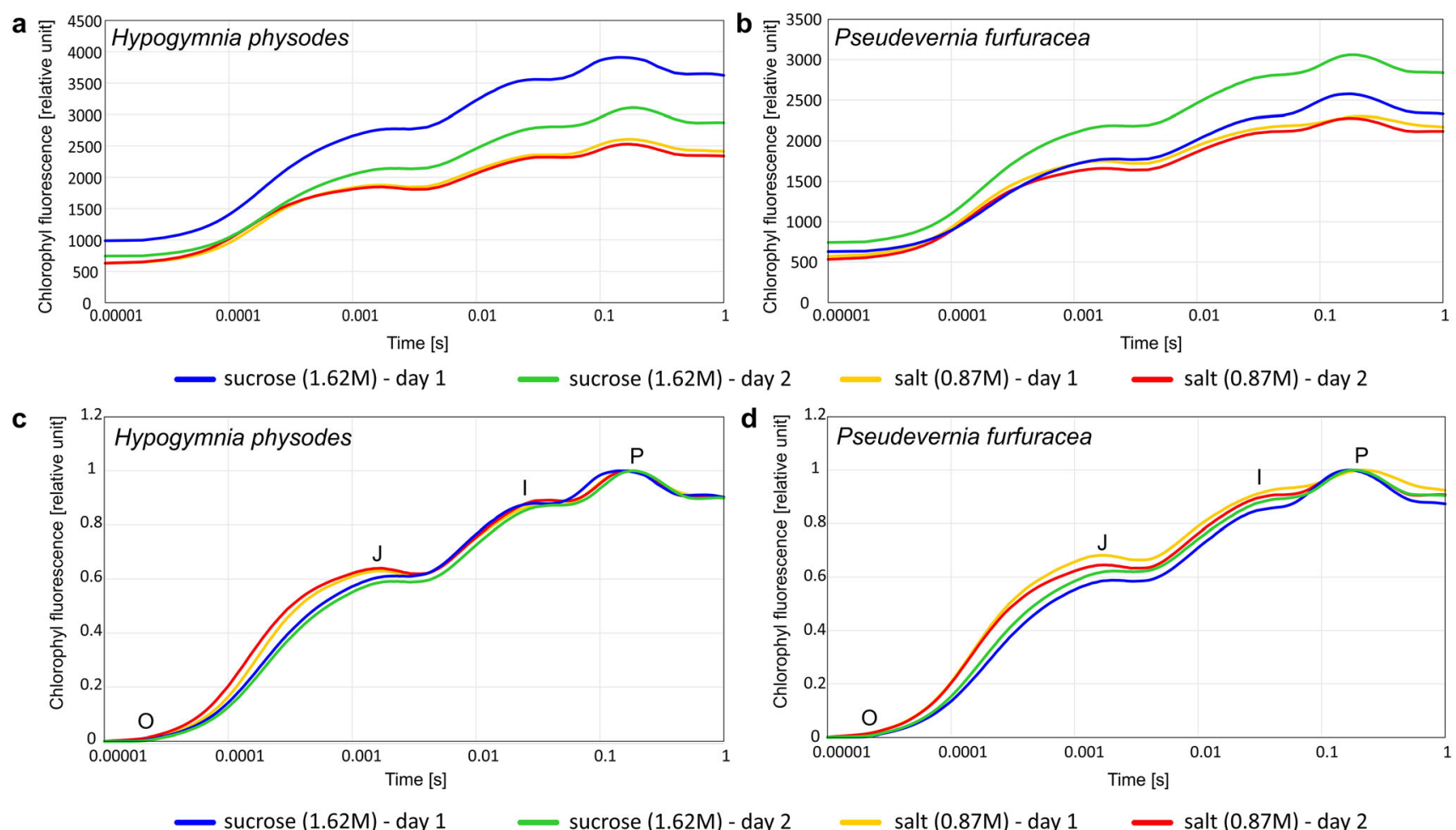

Fig. 2 Chlorophyll fluorescence induction curves (log time scale) for Hypogymnia physodes $(\mathbf{a}, \mathbf{c})$ and Pseudevernia furfuracea $(\mathbf{b}, \mathbf{d})$ treated with salt solution $(0.87 \mathrm{M})$ and sucrose solution $(1.62 \mathrm{M})$

characterised by the same osmotic pressure $(\pi=39504 \mathrm{hPa})$ on the first and the second day of the experiment. The transient curves $(\mathbf{c}, \mathbf{d})$ are double normalised to $F_{O}$ and $F_{M}$

decrease in $F_{V} / F_{M}$ in Lasallia pustulata and Umbilicaria hirsuta; however, full loss of functioning primary photochemistry in PS II was observed after treatment with $2.5 \mathrm{M}$ sucrose for $24 \mathrm{~h}$. This could explain the lack of a significant response of the studied species to short-term sucrose stress.

\section{Fluorescence kinetics and selected parameters of fluorescence}

OJIP fluorescence rise shape follows from changes in photosynthetic electron transport and the curve shows the successive reduction of electron transport pool of PSII (Govindjee 1995; Strasser et al. 2004). The trajectory of the curve provides information about the structure and functioning of the photosynthetic apparatus (Schreiber et al. 1994) and the shape of the OJIP transient has been found to be very sensitive to various kinds of environmental stress (Strasser et al. 2004). Our results showed that salt stress induced marked changes in the course of the fluorescence curve especially in the case of $H$. physodes (Figs. 2 and S5). On the contrary, the short-term osmotic stress caused by sucrose had no significant effect. The increase in $\mathrm{NaCl}$ concentration caused the decrease in $F_{M}$, and it could result from the inhibition of electron transport on the donor side of PSII. The important issue is the assessment of whether

$F_{V} / F_{M}$ decline, observed in both lichen species under salt stress, was due to the increase in $F_{O}$ or variations of other components. The increase in minimal fluorescence intensity observed in $P$. furfuracea under salt stress may be due to mechanisms similar to those in plants, in which it was proved to indicate destruction or malfunction of PSII reaction centre or disruption in electron transport for excitation of reaction centres (Bolhar-Nordenkampf et al. 1989). The decreased values of $F_{M}$ observed under salt stress indicate the accumulation of inactive reaction centres at PSII (Kalaji et al. 2011) and can be connected with cyclic electron transport within and around PSII and decrease in efficiency of the water splitting enzyme complex (Aro et al. 1993). In the case of $P$. furfuracea, we observed both rise in $F_{O}$ and a decrease in $F_{M}$, which resulted in a decrease of $F_{V} / F_{M}$ values. On the other hand, the decrease in $F_{V} / F_{M}$ under salt stress in $H$. physodes was mainly associated with a decrease in both $F_{M}$ and $F_{O}$ values. This indicates the increase in the rate constant of nonradiative energy dissipation that leads to a decrease in both minimal fluorescence intensity and maximal fluorescence intensity at closed PSII traps (Kitajima and Butler 1975). In contrast, in the case of $P$. furfuracea, only a decrease in the rate constant for PSII photochemistry could be recognized, which led to a rise in $F_{0}$. Our results showed that the shortterm osmotic stress caused by sucrose did not cause such a 
significant effect on either $F_{V} / F_{M}$ or changes in the trajectory of the fluorescence curve. It is worth noting, however, that the same trend of the increased $F_{O}$ values in the case of $P$. furfuracea and decreased in the case of $H$. physodes due to sucrose stress was observed immediately after incubation. The study on Lasallia pustulata and Umbilicaria hirsuta showed that osmotic stress induced by sucrose caused no change or increase in $F_{O}$ at low sucrose concentrations, while high concentrations caused a dramatic decrease in $F_{O}$ (Hajek et al. 2006). This could also support the fact that the response to both salt and sucrose stress was greater in $H$. physodes. The manner of the response certainly depends on the stress factor under consideration. With regard to lichens, the decrease in $F_{O}$ was caused by light stress (Balarinová et al. 2014) desiccation (Bednaříková et al. 2020) and biocides (Vannini et al. 2018); whereas the increase in $F_{O}$ was induced by polycyclic aromatic hydrocarbons (Kummerová et al. 2006).

The results showed that incubation of lichens in high salt concentrations lead to a considerable increase in specific absorption flux per reaction centre (ABS/RC) and dissipation energy flux per reaction centre $\left(\mathrm{DI}_{0} / \mathrm{RC}\right)$; whereas Phi $\left(\mathrm{R}_{0}\right), \mathrm{ET}_{0} / \mathrm{CS}, \mathrm{ET}_{0} / \mathrm{RC}$ and $\mathrm{PI}_{\mathrm{ABS}}$ were significantly decreased compared to the control. With regard to high salt concentrations, the changes of these parameters were significantly stronger than in the case of $F_{V} / F_{M}$ (Fig. S3). It can therefore be concluded that even if the $F_{V} / F_{M}$ values are decreased due to stress, they may still remain at a high level in the range characteristic for healthy lichens, and in such cases the changes in these parameters may be a better determinant of salt stress. Akhter et al. (2021) found that salt treatment caused changes in OJIP curves in both salttolerant and salt-sensitive Hordeum vulgare genotypes. In this case, photoinhibition of PSII was mainly due to enhanced inactive reaction centres, reduced specific absorption flux per reaction centre (ABS/RC), low electron transport flux per reaction centre $\left(\mathrm{ET}_{0} / \mathrm{RC}\right)$ and decreased primary photochemistry $\left(\mathrm{Phi}\left(\mathrm{P}_{0}\right), \mathrm{TR}_{0} / \mathrm{RC}\right)$. The increase of $\mathrm{ABS} / \mathrm{RC}$ has been frequently observed in plants under drought stress (Van Heerden et al. 2007; Mehta et al. 2010; Gomes et al. 2012). Such a phenomenon could be explained by inactivation of some PSII RCs or an increase in antenna size (Kalaji et al. 2016). Nevertheless, the response depends on the sensitivity of the species in question and so, for example, $\mathrm{ABS} / \mathrm{RC}$ and $\mathrm{TR}_{0} / \mathrm{RC}$ parameters increased after $60 \mathrm{~min}$ of photoinhibitory treatment in Usnea antarctica, whereas in U. aurantiacoatra decreased (Balarinová et al. 2014). The study on Dermatocarpon polyphyllizum showed that after desiccation $\mathrm{TR}_{0} / \mathrm{RC}$ and $\mathrm{ABS} / \mathrm{RC}$ increased and this may indicate that the number of active reaction centres is limited by the dehydration process (Bednař́ḱková et al. 2020). The observed elevated level of dissipation energy flux per reaction centre $\left(\mathrm{DI}_{0} / \mathrm{RC}\right)$ could be interpreted as an agent to protect PSII from photooxidative damage in the thylakoids membrane (Akhter et al. 2021). Both lichen species showed a much slower electron transport flux per excited cross-section $\left(\mathrm{ET}_{0} / \mathrm{CS}\right)$ than the control samples under salt stress conditions. This could be associated with the inactivation of the reaction centre complex as it was observed in Triticum aestivum leaves after the treatment with various $\mathrm{NaCl}$ concentrations (Mehta et al. 2010). Malaspina et al. (2014b) obtained similar results after exposure of $P$. furfuracea to shady or light conditions. They reported a reduction of $\mathrm{ET}_{0} / \mathrm{CS}$ and Phi $\left(\mathrm{E}_{0}\right)$ in light samples compared to shady ones which suggested malfunction of electron transport. They also observed that $F_{O}$ and ABS/CS are late indicators of stress since differences between experimental groups were visible until after four weeks. The decrease of Phi $\left(\mathrm{E}_{0}\right)$, Psi $\left(\mathrm{E}_{0}\right)$ and $\mathrm{ET}_{0} / \mathrm{RC}$ with the simultaneous increase in $\mathrm{DI}_{0} / \mathrm{RC}$ was also observed due to the temperature drop in the lichen Dermatocarpon polyphyllizum (Marečková et al. 2019).

The $\mathrm{PI}_{\mathrm{ABS}}$ constitutes a global indicator of the photosynthetic performance and indicates the overall vitality of the samples (Strasser et al. 2000). This parameter merges three functional steps of the photosynthetic activity (light absorption, excitation energy trapping, and electron transport), thus regarded as a very sensitive indicator of various kinds of stress in ecophysiological and environmental studies (Strasser et al. 2004). Our results also confirmed a stronger decrease of this parameter compared to $F_{V} / F_{M}$ due to salt stress. Similar observations were made in Evernia prunastri and $P$. furfuracea exposed to $\mathrm{NH}_{3}$ from livestock husbandry (Paoli et al. 2010). Nevertheless, another type of stress factor such as light stress can induce in lichens different effects depending on the species. For example, after 60 min of photoinhibition $\mathrm{PI}_{\mathrm{ABS}}$ values increased in $U$. aurantiaco-atra, but the same treatment in $U$. antarctica resulted in a decrease of $\mathrm{PI}_{\mathrm{ABS}}$ (Balarinová et al. 2014). On the contrary, the study on Pleurosticta acetabulum showed that extreme UVB radiation did not cause significant differences between experimental and control samples (Kyriatzi et al. 2021).

The maximum quantum yield of PSII photochemistry is one of the most frequently measured parameters in studies dealing with the influence of stress factors on plants and lichens. However, the results presented in this study prove that the values of other fluorescence parameters, e.g. those determining the electron transport efficiency or the minimal fluorescence intensity, can provide a lot of additional information about the physiological state of the photosynthetic apparatus. In the case of many parameters, the changes caused by salt stress were stronger than the changes in the $F_{V} / F_{M}$ parameter. Therefore, these 
parameters may be better indicators of the impact of salt stress on lichens and should be analysed in further studies.

\section{Ionic and osmotic effects of salt stress}

Salt stress includes both osmotic stress and ionic toxicity (Mehta et al. 2010); however, it is difficult to assess unequivocally the relative importance of these two mechanisms as they overlap. Apart from osmotic stress induced by incubation of lichen thalli in the salt solution, a rapid uptake of ions to both intracellular and extracellular fractions occurs (Matos et al. 2011). This highlights the importance of determining the cellular location of elements in the context of studying the influence of ionic stress on lichen physiology. The results of the present study showed that solutions of salt and sucrose with the same osmotic pressure have a different effect on photosynthetic efficiency. The experiment showed that salt stress had a more negative impact on photosynthetic efficiency in comparison to control values than that of sucrose, which directly suggests additional negative effects of $\mathrm{Na}^{+}$and $\mathrm{Cl}^{-}$on photosynthesis. In the case of $P$. furfuracea, many fluorescence parameters can be considered as early indicators of salt-induced changes however no drastic reduction was observed in the $F_{V} / F_{M}$ as compared to the effects caused by salt and sucrose solutions with the same osmotic pressure. It concerns the decrease in the transfer of electrons per reaction centre and quantum yield of electron transport. It may also indicate the first effects be related to the impact of the ionic component of salt stress. The most symptomatic change was observed as the significant reduction in $\mathrm{ET}_{0} / \mathrm{RC}$ after treatment with salt solutions compared to both the control sucrose solution with the same osmotic pressure. This indicates a significant reduction of the utilisation of trapped energy in electron transport and thereby down-regulation of electron transfer. Hypogymnia physodes was characterised by a stronger response, since the studied parameters including $F_{V} / F_{M}$ and $\mathrm{PI}_{\mathrm{ABS}}$ were found significantly reduced due to osmotic stress induced by ionic $(\mathrm{NaCl})$ solution compared to non-ionic (sucrose) solution.

Moreover, the course of fluorescence induction curves for salt and sugar treatments were significantly different. Raw OJIP transients showed that lichen samples subjected to salt stress had a decreased fluorescence mainly at I and P steps compared to samples treated with sucrose solution. The greater reduction in the fluorescence emission at these steps was also reported in different Hordeum vulgare genotypes subjected to salinity stress (Akhter et al. 2021). The double normalised transient curves showed that the main differences are associated with the O-J rise, whereas a significantly faster increase was observed in the case of lichens treated with salt solution compared to sucrose. The
O-J phase corresponds to the photochemical reduction of the primary quinone electron acceptor of PS II $\left(\mathrm{Q}_{\mathrm{A}}\right)$ and accumulation of $\mathrm{Q}_{\mathrm{A}}{ }^{-}$(Strasser and Govindjee 1992; Kalaji et al. 2016). Consequently, a growth in this phase could indicate the reduction of PSII acceptor $\left(\mathrm{Q}_{\mathrm{A}}\right)$ (Boisvert et al. 2006). The prominent decrease in chlorophyll fluorescence signal and more flattened OJIP curve induced by salt stress was also found in freshwater algae and cyanobacteria (Zhang et al. 2010; Vilumbrales et al. 2013).

\section{Conclusions}

Our results show that the short-term salt stress leads to a significant reduction of $F_{V} / F_{M}$ and greater changes in chlorophyll fluorescence parameters and OJIP transient curve compared to the osmotic stress induced by sucrose. This proved that salt stress is associated not only with the osmotic stress that causes physiological drought by cell dehydration but also with negative effects of excessive accumulation of ions in cells (ionic stress). The most symptomatic effect of the ionic stress observed a significant reduction in the utilisation of trapped energy in electron transport and thereby down-regulation of electron transfer. In the case of lichens, which are poikilohydric organisms resistant to temporary lack of water availability, ionic stress associated with accumulation of ions in the cells have much more serious consequences especially when these consequences were compared with vascular plants vulnerable to drought stress.

Both the first and the second stage of the experiment showed that $H$. physodes is more sensitive to salt stress than $P$. furfuracea. The greater sensitivity of $H$. physodes to salt stress was evidenced not only by stronger decrease in $F_{V} / F_{M}$ values, but also by greater changes in chlorophyll fluorescence parameters and stronger deviation in OJIP transient curve compared to the control treatment.

The maximum quantum yield of PSII photochemistry is one of the most widely studied parameters describing photosynthetic performance of plants and lichens exposed to stress factors. However, the results showed that changes of other fluorescence parameters could be more informative and provide a lot of additional information about the physiological state of the photosynthetic apparatus. In the case of many parameters, the changes caused by salt stress were stronger than the changes in the $F_{V} / F_{M}$ parameter compared to control. Consequently, these parameters could be better indicators of the impact of salt stress on lichens.

The results showed that exposure to short-term salt stress reduces the photosynthetic efficiency, but does not cause permanent changes, because after $24 \mathrm{~h}$ from exposure to stress, $F_{V} / F_{M}$ values increased and in most of experimental groups returned to the level characteristic for 
healthy lichens. Nevertheless, short-term but repeated episodes of exposure to salt stress may reduce the vitality of lichens inhabiting the substrates along communication routes which may result in a consequence to the death of the lichen thallus. In many countries the period of salt sprinkling on roads is very long, so it is important to look for alternatives to road salt with a less harmful impact on the surrounding environment.

Author contributions Karolina Chowaniec Methodology, Formal analysis, Investigation, Writing-original draft preparation, Visualization. Kaja Rola: Conceptualization, Methodology, Formal analysis, Investigation, Writing — review and editing, Visualization, Funding acquisition, Resources, Supervision.

Funding Partial financial support was received from the Institute of Botany at the Jagiellonian University, project no. N18/DBS/000002.

\section{Declarations}

Conflict of interest The authors declare no conflicts of interest.

Supplementary Information The online version contains supplementary material available at https://doi.org/10.1007/s12298022-01134-2.

Open Access This article is licensed under a Creative Commons Attribution 4.0 International License, which permits use, sharing, adaptation, distribution and reproduction in any medium or format, as long as you give appropriate credit to the original author(s) and the source, provide a link to the Creative Commons licence, and indicate if changes were made. The images or other third party material in this article are included in the article's Creative Commons licence, unless indicated otherwise in a credit line to the material. If material is not included in the article's Creative Commons licence and your intended use is not permitted by statutory regulation or exceeds the permitted use, you will need to obtain permission directly from the copyright holder. To view a copy of this licence, visit http://creativecommons. org/licenses/by/4.0/

\section{References}

Ahmadjian V (1993) The lichen photobiont: what can it tell us about lichen systematics? Bryologist 96:310-313. https://doi.org/10. 2307/3243858

Akhter MS, Noreen S, Mahmood S, Athar HR, Ashraf M, Alsahli AA, Ahmad P (2021) Influence of salinity stress on PSII in barley (Hordeum vulgare L.) genotypes, probed by chlorophyll-a fluorescence. J King Saud Univ Sci 33:101239. https://doi.org/ 10.1016/j.jksus.2020.101239

Aro EM, Virgin I, Andersson B (1993) Photoinhibition of photosystem II. Inactivation, protein damage and turnover. Biochim Biophys Acta 1143:113-134. https://doi.org/10.1016/00052728(93)90134-2

Balarinová K, Barták M, Hazdrová J, Hájek J, Jílková J (2014) Changes in photosynthesis, pigment composition and glutathione contents in two Antarctic lichens during a light stress and recovery. Photosynthetica 52:538-547. https://doi.org/10.1007/ s11099-014-0060-7
Beckett RP, Mayaba N, Minibayeva FV, Alyabyev AJ (2005) Hardening by partial dehydration and $\mathrm{ABA}$ increase desiccation tolerance in the cyanobacterial lichen Peltigera polydactylon. Ann Bot 96:109-115. https://doi.org/10.1093/aob/mci156

Bednaříková M, Váczi P, Lazár D, Barták M (2020) Photosynthetic performance of Antarctic lichen Dermatocarpon polyphyllizum when affected by desiccation and low temperatures. Photosynth Res 145:159-177. https://doi.org/10.1007/s11120-020-00773-4

Boisvert S, Joly D, Carpentier R (2006) Quantitative analysis of the experimental O-J-I-P chlorophyll fluorescence induction kinetics: apparent activation energy and origin of each kinetic step. FEBS J 273:4770-4777. https://doi.org/10.1111/j.1742-4658. 2006.05475.x

Bolhar-Nordenkampf HR, Long SP, Baker NR, Oquist G, Schreiber U, Lechner EG (1989) Chlorophyll fluorescence as a probe of the photosynthetic competence of leaves in the field: a review of current instrumentation. Funct Ecol 3:497-514. https://doi.org/ $10.2307 / 2389624$

Buck GW, Brown DH (1979) The effect of desiccation on cation location in lichens. Ann Bot 44:265-277. https://doi.org/10. 1093/oxfordjournals.aob.a085730

Delmail D, Grube M, Parrot D, Cook-Moreau J, Boustie J, Labrousse P, Tomasi S (2013) Halotolerance. In: lichens: symbiotic coalition against salt stress. In: Prasad MNV, Ahmad P, Azooz MM (eds) Ecophysiology and responses of plants under salt stress. Springer, New York, USA, pp 115-148

Erdmann N, Hagemann M (2001) Salt acclimation of algae and cyanobacteria: a comparison. In: Rai LC, Gaur JP (eds) Algal adaptation to environmental stresses: physiological, biochemical and molecular mechanisms, 1st edn. Berlin, Heidelberg, pp 323-361

Gasulla F, Guéra A, de Ríos Los A, Pérez-Ortega S (2019) Differential responses to salt concentrations of lichen photobiont strains isolated from lichens occurring in different littoral zones. Plant Fungal Sys 64(149):162. https://doi.org/10.2478/pfs-20190016

Gomes MTG, da Luz AC, dos Santos MR, Batitucci MDCP, Silva DM, Falqueto AR (2012) Drought tolerance of passion fruit plants assessed by the OJIP chlorophyll a fluorescence transient. Sci Hortic 142:49-56. https://doi.org/10.1016/j.scienta.2012.04. 026

Govindjee J (1995) Sixty-three years since Kautsky: chlorophyll a fluorescence. Aust J Plant Physiol 22:131-160. https://doi.org/ 10.1071/PP9950131

Green TGA, Sancho LG, Pintado A (2011) Ecophysiology of desiccation/rehydration cycles in mosses and lichens. In: Lüttge $\mathrm{U}$, Beck E, Bartels D (eds) Plant desiccation tolerance, ecological studies 215. Springer, Berlin, pp 89-120

Grube M, Blaha J (2005) Halotolerance and lichen symbioses. In: N Gunde Cimerman, A Oren, A Plemenitas (eds). Adaptation to life at high salt concentrations in archaea, bacteria, and eukarya. Cellular origin, life in extreme habitats and astrobiology. Springer, Dordrecht, pp 471-488

Hájek J, Barták M, Dubová J (2006) Inhibition of photosynthetic processes in foliose lichens induced by temperature and osmotic stress. Biol Plant 50:624-634. https://doi.org/10.1007/s10535006-0098-x

Hasegawa PM, Bressan R, Zhu JK, Bohnert HJ (2000) Plant cellular and molecular responses to high salinity. Annu Rev Plant Physiol Plant Mol Biol 51:463-499. https://doi.org/10.1146/ annurev.arplant.51.1.463

Hinojosa-Vidal E, Marco F, Martinez-Alberola F, Escaray FJ, GarciaBreijo F, Reig-Arminana J, Carrasco P, Barreno E (2018) Characterization of the responses to saline stress in the symbiotic green microalga Trebouxia sp. TR9. Planta 248:1473-1486. https://doi.org/10.1007/s00425-018-2993-8 
Honegger R (2007) Water relations in lichens. In: Gadd GM, Watkinson SC, Dyer P (eds) Fungi in environment. Cambridge, pp 185-200

Incerti G, Cecconi E, Capozzi F et al (2017) Infraspecific variability in baseline element composition of the epiphytic lichen Pseudevernia furfuracea in remote areas: implications for biomonitoring of air pollution. Environ Sci Pollut Res 24:8004-8016. https://doi.org/10.1007/s11356-017-8486-7

Jensen M, Kricke R (2002) Chlorophyll fluorescence measurements in the field: assessment of the vitality of large numbers of lichen thalli. In: Nimis PL, Scheidegger C, Wolseley PA (eds) Monitoring with lichens - monitoring lichens. Kluwer Academic Publishers, Wales, pp 327-332

Kalaji HM, Jajoo A, Oukarroum A, Brestic M, Zivcak M, Samborska IA, Cetner MD, Łukasik I, Goltsev V, Ladle RL (2016) Chlorophyll a fluorescence as a tool to monitor physiological status of plants under abiotic stress conditions. Acta Physiol Plant 38:102. https://doi.org/10.1007/s11738-016-2113-y

Kalaji HM, Račková L, Paganová V, Swoczyna T, Rusinowski S, Sitko K (2018) Can chlorophyll-a fluorescence parameters be used as bio-indicators to distinguish between drought and salinity stress in Tilia cordata Mill? Environ Exp Bot 152:149-157. https://doi.org/10.1016/j.envexpbot.2017.11.001

Kalaji HM (2011) Influence of abiotic stress factors on chlorophyll fluorescence in selected varieties of barley Hordeum vulgare L. plants. Szkoła Główna Gospodarstwa Wiejskiego, Warszawa [in Polish].

Kitajima M, Butler WL (1975) Quenching of chlorophyll fluorescence and primary photochemistry in chloroplasts by dibromothymoquinone. Biochim Biophys Acta 376:105-115. https:// doi.org/10.1016/0005-2728(75)90209-1

Kosugi M, Arita S, Shizuma R, Moriyama Y, Kashino Y, Koike H, Satoh K (2009) Responses to desiccation stress in lichens are different from those in their photobionts. Plant Cell Physiol 50:879-888. https://doi.org/10.1093/pcp/pcp043

Kranner I, Zorn M, Turk B, Wornik S, Beckett RP, Batic F (2003) Biochemical traits of lichens differing in relative desiccation tolerance. New Phytol 160:167-176. https://doi.org/10.1046/j. 1469-8137.2003.00852.x

Kranner I, Cram WJ, Zorn M, Wornik S, Yoshimura I, Stabentheiner E, Pfeifhofer HW (2005) Antioxidants and photoprotection in a lichen as compared with its isolated symbiotic partners. Proc Natl Acad Sci USA 102:3141-3146. https://doi.org/10.1073/ pnas.0407716102

Kranner I, Beckett R, Hochman A, Nash TH (2008) Desiccationtolerance in lichens: a review. Bryologist 111:576-593. https:// doi.org/10.1639/0007-2745-111.4.576

Kummerová M, Barták M, Dubová J, Tříska J, Zubrová E, Zezulka Š (2006) Inhibitory effect of fluoranthene on photosynthetic processes in lichens detected by chlorophyll fluorescence. Ecotoxicology 15:121-131. https://doi.org/10.1007/s10646-0050037-1

Kyriatzi A, Tzivras G, Pirintso S, Kotzabasis K (2021) Biotechnology under extreme conditions: lichens after extreme UVB radiation and extreme temperatures produce large amounts of hydrogen. J Biotechnol 342:128-138. https://doi.org/10.1016/j.jbiotec. 2021.10.011

Lange OL, Green TGA (2005) Lichens show that fungi can acclimate their respiration to seasonal changes in temperature. Oecologia 142:11-19. https://doi.org/10.1007/s00442-004-1697-x

Malaspina P, Giordani P, Faimali M, Garaventa F, Modenes P (2014a) Assessing photosynthetic biomarkers in lichen transplants exposed under different light regimes. Ecol Indic 43:126-131. https://doi.org/10.1016/j.ecolind.2014.02.034

Malaspina P, Giordani P, Modenesi P, Abelmoschi ML, Magi E, Soggia F (2014b) Bioaccumulation capacity of two chemical varieties of the lichen Pseudevernia furfuracea. Ecol Indic 45:605-610. https://doi.org/10.1016/j.ecolind.2014.05.026

Malaspina P, Giordani P, Pastorino G, Modenesi P, Mariotti G, Mauro $G$ (2015) Interaction of sea salt and atmospheric pollution alters the OJIP fluorescence transient in the lichen Pseudevernia furfuracea (L.) Zopf. Ecol Indic 50:251-257. https://doi.org/10. 1016/j.ecolind.2014.11.015

Malaspina P, Giordani MP, P, (2018) Physiological response of two varieties of the lichen Pseudevernia furfuracea to atmospheric pollution. Ecol Indic 86:27-34. https://doi.org/10.1016/j.ecolind. 2017.12.028

Marečková M, Barták M, Hájek J (2019) Temperature effects on photosynthetic performance of Antarctic lichen Dermatocarpon polyphyllizum: a chlorophyll fluorescence study. Polar Biol 42:685-701. https://doi.org/10.1007/s00300-019-02464-w

Matos P, Cardoso-Vilhena J, Figueira R, Sousa AJ (2011) Effects of salinity stress on cellular location of elements and photosynthesis in Ramalina canariensis Steiner. Lichenologist 43:155-164. https://doi.org/10.1017/S0024282910000757

Matthes-Sears U, Nash TH, Larson DW (1987) Salt loading does not control $\mathrm{CO}_{2}$ exchange in Ramalina menziesii Tayl. New Phytol 106:59-69. https://doi.org/10.2307/2434686

Mehta P, Jajoo A, Mathur S, Bharti S (2010) Chlorophyll $a$ fluorescence study revealing effects of high salt stress on photosystem II in wheat leaves. Plant Physiol Biochem 48:16-20. https://doi. org/10.1016/j.plaphy.2009.10.006

Nash TH III, Lange OL (1988) Responses of lichens to salinity: concentration and time-course relationships and variability among Californian species. New Phytol 109:361-367

Nimis PL, Scheidegger C, Wolseley PA (2002) Monitoring with lichens - monitoring lichens. Kluwer Academic, Wales

Nimis PL (2016) ITALIC - The Information System on Italian Lichens. Version 5.0. University of Trieste, Dept. of Biology. http://dryades.units.it/italic. Accessed 23 August 2021

Pan T, Liu M, Kreslavski VD, Zharmukhamedov SK, Nie C, Yu M, Kuznetsov VV, Allakhverdiev SI, Shabala S (2021) Nonstomatal limitation of photosynthesis by soil salinity. Crit Rev Environ Sci Technol 51:791-825. https://doi.org/10.1080/ 10643389.2020.1735231

Paoli L, Pirintsos SA, Kotzabasis K, Pisani T, Navakoudis E, Loppi S (2010) Effects of ammonia from livestock farming on lichen photosynthesis. Environ Pollut 158:2258-2265. https://doi.org/ 10.1016/j.envpol.2010.02.008

Rusu AM, Jones GC, Chimonides PDJ, Purvis OW (2006) Biomonitoring using the lichen Hypogymnia physodes and bark samples near Zlatna, Romania immediately following closure of a copper ore-processing plant. Environ Pollut 143:81-88. https://doi.org/ 10.1016/j.envpol.2005.11.002

Schreiber U, Bilger W, Neubauer C (1994) Chlorophyll fluorescence as a nonintrusive indicator for rapid assessment of in vivo photosynthesis. In: Schulze ED, Caldwell MM (eds) Ecophysiology of photosynthesis, 1st edn. Springer, Berlin, pp 49-70

Smith VR, Gremmen NJM (2008) Photosynthesis in a sub-Antarctic shore-zone lichen. New Phytol 149:291-299. https://doi.org/10. 1046/j.1469-8137.2001.00025.x

Strasser RJ, Srivastava A, Tsimilli-Michael M (2000) The fluorescence transient as a tool to characterize and screen photosynthetic samples. In: Yunus M, Pathre U, Mohanty P (eds) Probing photosynthesis: mechanism, regulation and adaptation, 1st edn. Taylor and Francis, London, pp 443-480

Strasser RJ, Tsimilli Michael M, Srivastava A (2004) Analysis of the chlorophyll a fluorescence transient. In: Papageorgiou GC, Govindjee J (eds) Chlorophyll a fluorescence advances in photosynthesis and respiration. Springer, Dordrecht, pp 321-362

Strasser RJ, Govindjee J (1992) On the OJIP fluorescence transients in leaves and mutants of Chlamydomonas reinhardtii. In: N Murata 
(eds) Research in photosynthesis proceedings of the International Congress on Photosynthesis, Kluwer Academic Publishers, The Netherlands. pp 29-32

Tyler G (1989) Uptake, retention, and toxicity of heavy metals in lichens. Water Air Soil Pollut 47:321-333

Van Heerden PDR, Swanepoel JW, Krüger GHJ (2007) Modulation of photosynthesis by drought in two desert scrub species exhibiting $\mathrm{C} 3$-mode $\mathrm{CO} 2$ assimilation. Environ Exp Bot 61:124-136. https://doi.org/10.1016/j.envexpbot.2007.05.005

Vannini A, Contardo T, Paoli L, Scattoni M, Favero-Longo SE, Loppi S (2018) Application of commercial biocides to lichens: does a physiological recovery occur over time? Int Biodeterior Biodegradation 129:189-194. https://doi.org/10.1016/j.ibiod. 2018.02.010

Vilumbrales DM, Skácelová K, Barták M (2013) Sensitivity of Antarctic freshwater algae to salt stress assessed by fast chlorophyll fluorescence transient. Czech Polar Rep 3:163-172. https://doi.org/10.5817/CPR2013-2-17
Yemets O, Gauslaa Y, Solhaug KS (2015) Monitoring with lichens conductivity methods assess salt and heavy metal damage more efficiently than chlorophyll fluorescence. Ecol Indic 55:59-64. https://doi.org/10.1016/j.ecolind.2015.03.015

Zhang T, Gong H, Wen X, Lu C (2010) Salt stress induces a decrease in excitation energy transfer from phycobilisomes to photosystem II but an increase to photosystem I in the cyanobacterium Spirulina platensis. J Plant Physiol 167:951-958. https://doi.org/ 10.1016/j.jplph.2009.12.020

Zhao C, Zayed O, Zeng F, Liu C, Zhang L, Zhu P, Hsu CC, Tuncil YE, Tao WA, Carpita NC, Zhu JK (2019) Arabinose biosynthesis is critical for salt stress tolerance in Arabidopsis. New Phytol 224:274-290. https://doi.org/10.1111/nph.15867

Publisher's Note Springer Nature remains neutral with regard to jurisdictional claims in published maps and institutional affiliations. 